\title{
Progress on Collection, Treatment and Utilization of Solid Waste
}

\author{
Shang Shuyong ${ }^{1}$, Mei Li ${ }^{1, ~ *}$, Zhang Yudie ${ }^{2}$, Huang Fei ${ }^{2}$, Wang Bing ${ }^{2}$, Li Weiyi ${ }^{2}$ \\ ${ }^{1}$ School of Chemistry and Life Science, Chengdu Normal University, Chengdu, Sichuan, P. R. China \\ ${ }^{2}$ Research Institute of Chemical Engineering and Technology, Yibin University, Yibin, Sichuan, P. R. China
}

Email address:

16068676@qq.com (Mei Li)

${ }^{*}$ Corresponding author

To cite this article:

Shang Shuyong, Mei Li, Zhang Yudie, Huang Fei, Wang Bing, Li Weiyi. Progress on Collection, Treatment and Utilization of Solid Waste. American Journal of Chemical Engineering. Vol. 4, No. 2, 2016, pp. 52-56. doi: 10.11648/j.ajche.20160402.14

Received: February 27, 2016; Accepted: May 12, 2016; Published: May 19, 2016

\begin{abstract}
With more and more serious impact on the environment by solid waste, the collection, treatment and utilization of solid waste have become the research focus in the current. This article mainly generalizes the collection ways and treatment methods for the living garbage, industrial waste and agricultural waste. The resource utilization techniques of solid wasteincluding separation technology, incineration and pyrolytictechniques, biological treatment technology, energy recovery via RDF and incineration power generationare analyzed and discussed in detail. The results will provide some proper proposals for handling and reusing solid waste effectively and contribute to the social sustainable development, the low carbon economy and the eco-development.
\end{abstract}

Keywords: Solid Waste, Living Garbage, Industrial Waste, Agricultural Waste, Collection, Treatment, Resource Utilization

\section{Introduction}

With the rapid development of Chinese economy, the domestic medium and small city and rural now facing the threat of solid waste. The city garbage generated 490 million tons every year in the world, only China annually produce nearly 150 million tons [1]. Authority forecast the industrial enterprises including township enterprises of China produce solid waste and hazardous waste will reach 2310 million tons and 57 million tons in 2015, and the agricultural waste, including animal manure 2600 million tons, 700 million tons of crop straw, vegetable waste 100 million tons, forestry waste 50 million tons, mainly manure and straw in the first place [2]. In solid waste collection, treatment is very difficult, the collection and treatment of domestic garbage is relatively good, but harmless treatment rate is only $20 \%$. Industrial waste is mostly stacking disorderly in the deep, the handling capacity is small, and the resource utilization is seriously shortage. Disordered stacking of solid waste is seriously polluted, water, air, soil and other dead.

\section{Collection of Solid Waste}

\subsection{Collection of Daily Life Solid Waste}

Separate collection of garbage is a systematic project. Everyone, including government, enterprise, resident, and neglected their army, should participate in it. And each unit should cooperate with each other, and form a unified system. The classification of the source of garbage relates to everyone's life, only "principle to convenience" is a good implementation. According to this principle, China's waste classification management can take this pattern: Residents source classified "dry", "wet" garbage two, wet garbage directly to the waste treatment center for processing, dry refuse to scavengers cooperatives detailed classification, classification of Recyclable garbage to professional recycling companies, fine the classification of the unrecyclable garbage to the garbage disposal center to process [3]. Collection mode of household garbage as shown in Fig. 1. 


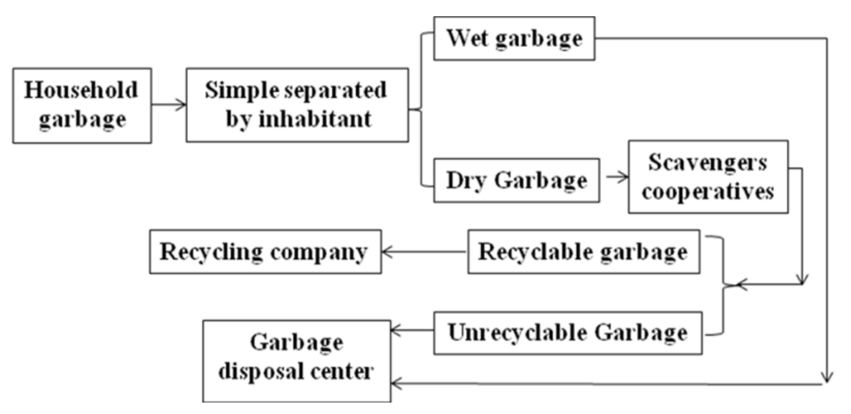

Fig. 1. Collection mode of household garbage.

\subsection{Collection of Industrial Solid Waste}

The variety of Industrial solid waste is various, usually including black metal, nonferrous metal, rubber, plastic, paper, cloth, linen, cotton, chemical fiber, human hair, animal bone, glass, metal bottle, electrical and mechanical hardware, chemical offal, waste oil and other 16 major categories of more than 1000 varieties. The industrial solid waste treatment in China is the principle of "who pollution, who control". For a specific enterprise:

Large enterprises: equipment management system and personnel specialized in the collection and transportation of self (Self-collection and transportation).

Medium-sized enterprises: regular recovery (Periodic Collection), dicing lump sum circuit recovery (Scheduled Collection)

Small enterprises: focus on recycling sector, processing by the recycling sector.

\subsection{Collection of Agricultural Solid Waste}

Collection of agricultural waste as shown in Fig. 2 [4].

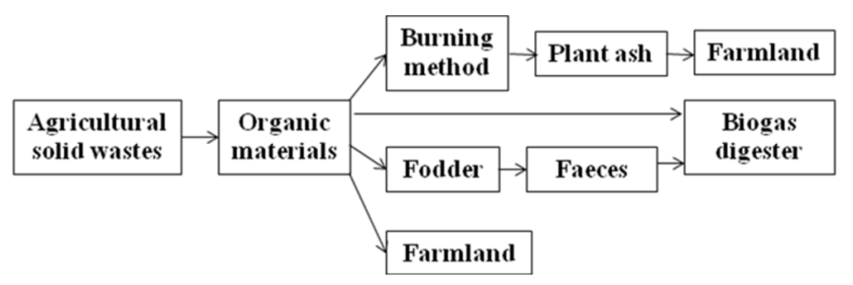

Fig. 2. Collection mode of agricultural solid waste.

\section{Solid Waste Treatment Technology}

\subsection{Landfill Treatment}

Solid fill treatment can be divided into the traditional landfill and sanitary landfill. Direct landfill is garbage fill compaction, cover ready pit, the method is simple, occurring the physical, biological, and chemical changes, to achieve reduction purposes, but easy to causing two pollution of groundwater resources, air pollution, and even serious will happen explosion [5]. Sanitary landfill is one of the most common disposal method, the typical process as shown in Fig. 3 , the cost is low compared to the traditional landfill. In addition, the greenhouse gas $\mathrm{CH}_{4}$ solid landfill each year around the world can statistics produced 22 36 million tons [6]. Landfill has many limitations, potential pollution and secondary pollution is still serious.

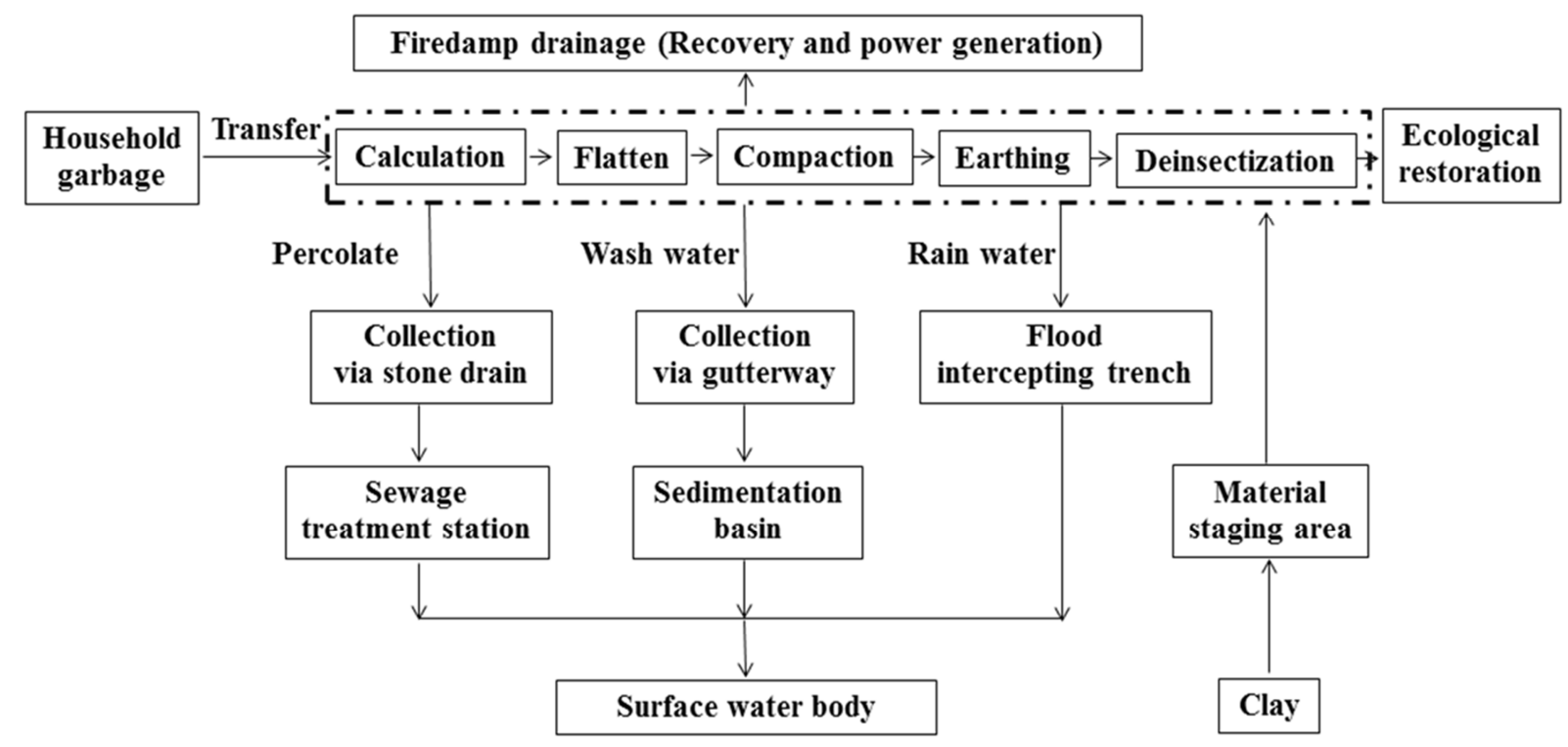

Fig. 3. Typical treatment process of domestic waste.

\subsection{Incineration Disposal}

Incineration disposal is a method of high temperature heat treatment of garbage, garbage combustible components in the high temperature furnace $\left(800 \sim 1000^{\circ} \mathrm{C}\right)$ react vigorously with oxygen, into the high temperature flue gas and solid slag, and release the heat. The general process of garbage incineration is in Fig. 4. Garbage incineration can reduce the volume of $80-90 \%$, some harmful substances by burning, can achieve the purpose of detoxification of pesticides, the heat generated in the incineration for power generation and heating, slag can be made into building materials brick [7]. But during the incineration, it will produce of dioxin, if not up to standard, a great threat to the environment. 


\section{Solid Waste Resource's Utilization}

\subsection{Separation Technology}

Separation of solid waste is an important means to realize the reduction, resource recovery of solid waste, by separating the useful substances elected to use, the harmful substances fully separated; another is the different granularity levels of waste to be separated [8]. According to the different nature, can design and manufacture all kinds of machine to separate of solid waste, including manual sorting, screening, separation, gravity separation, magnetic separation, eddy current separation, optical sorting. City life garbage is in the rapid growth of $8-10 \%$ a year [9], separation technology is effective for treatment of domestic garbage sorting technology, but only waste resource utilization as a necessary step, not fully realize the resource waste. In addition, Li Zehui et al [10] do some research in separation technology, such as according to the different functional groups of organic produce corresponding spectra in the infrared radiation of infrared absorption spectrum analysis technique for sorting, image recognition technology mainly for specific garbage for sorting (by industrial camera shooting, feedback to the computer control system sorting), variable weight sorting is innovation sorting of light substance (mainly through the hydrophilic differences), temperature sensing technology, based on the study of traditional technique and new technical proposals, and the rise in other areas of technology will change into the field, in order to improve municipal solid waste harmless and resources degree, construction is conducive to environmental protection and sustainable development of the society.

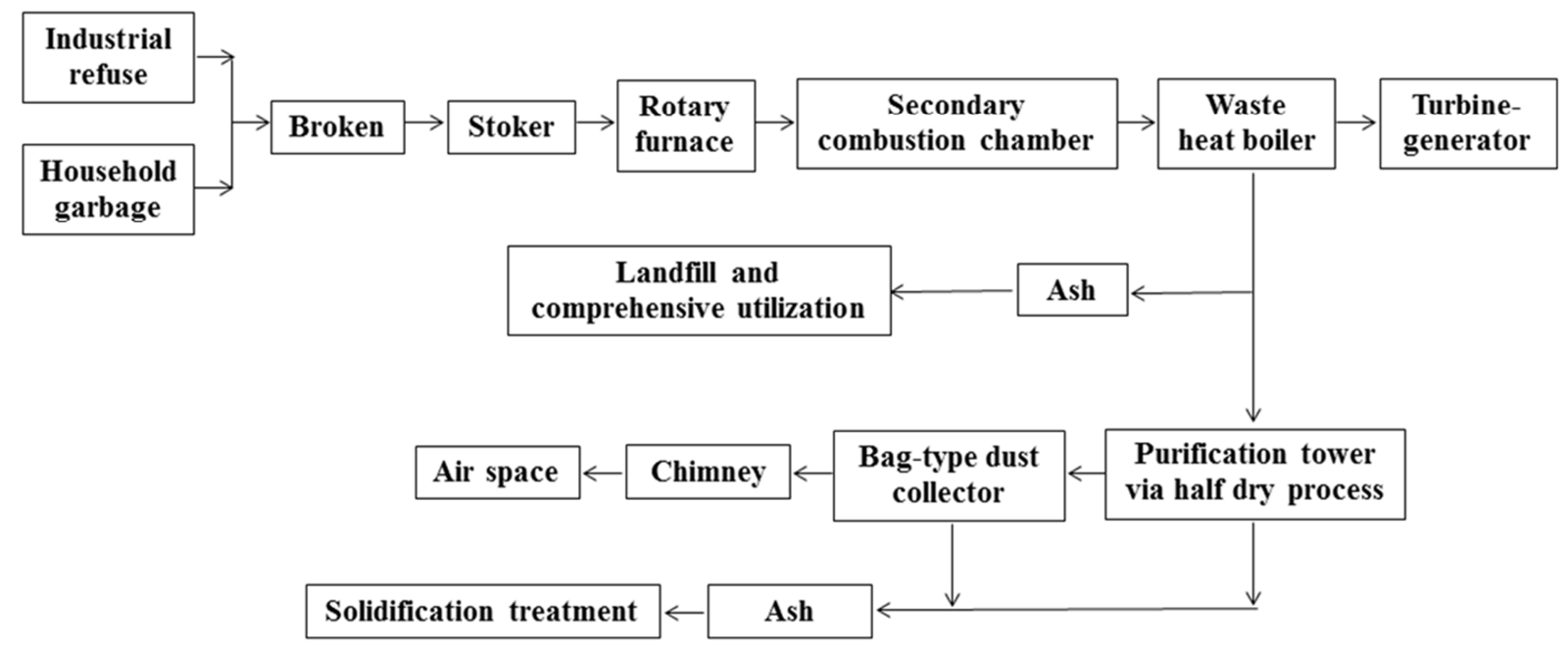

Fig. 4. Process of garbage incineration.

\subsection{Incineration and Pyrolytic Techniques}

Incineration is the comprehensive treatment of solid waste pyrolysis and oxidation process, the benefit is a lot of harmful waste decomposition into harmless substances. Incineration is a good weight reduction effect (reduce the residue after burning for more than $90 \%$ of the volume, weight reduction of more than $80 \%$ ), thorough treatment [11]. However, the construction and production cost of incineration plant is very expensive, and high toxicity, easy to produce two environmental hazards. At present, the incineration plant is only 69 , processing capacity of 11380000 tons.

In addition, plasma treatment of garbage incineration and pyrolysis technology also belongs to. Plasma is a form of existence of fourth substances in addition to solid, liquid and gaseous, containing a large number of high energy electrons, ions, free radicals, excited molecules and other active particles [12]. Particle energy up to several tens of EV, greater than the combination of polymeric material can. Plasma technology to generate plasma up to $7000 \mathrm{C}$ by arc discharge, rubbish will be heated to a high temperature, thereby destroying waste quickly and effectively. Organic ingredients fully pyrolysis gasification of combustible, conversion to synthesis gas $(\mathrm{CO}+$ $\mathrm{H}_{2}$ ), other substances into the slag similar vitreous [13].
Synthesis gas for power generation, can also be used for the production of ethanol, methanol and bio diesel; slag can be processed into building materials [14]. The problems in the actual production of Wang Mingfei [15] and others made countermeasures and solutions. Such as the generation of dioxin is controlled by two methods, using the "3T in the production" (temperature, turbulence and time) technology, the general temperature is more than $850^{\circ} \mathrm{C}$, residence time is more than $2 \mathrm{~s}$, using two times of the wind, so that combustion and air fully mixing, reducing dioxin precursor material production. Two plasma reactors are employedto produce synthesis gas by reforming, the export of synthetic gas temperature at $900^{\circ} \mathrm{C} \sim 1200^{\circ} \mathrm{C}$, the degree of dioxin removal rate was $99.9999 \%$. In the regeneration, they take the quench cooling to cook the flue gas, the flue gas quickly across the $500^{\circ} \mathrm{C} \sim 200^{\circ} \mathrm{C}$ as the regeneration temperature, the residence time of flue gas is controlled about $1 \mathrm{~s}$, strictly control the tightness in the air volume and the whole system of the gasifier, prevent air infiltration. And the tar conversion depends on the temperature and gas residence time, so it can achieve good effect through control, the residual tar can use alkaline spray washing and activated carbon adsorption, so as to use the standard; and the synthesis gas quality directly related to the gasification system tightness solution. 


\subsection{Biological Treatment Technology}

Composting is also called biological and processing technology. Biological treatment technology is the use of microbial decomposition of organic solid waste make it harmless can make the organic solid waste to energy, food, feed and fertilizer, can also be used for the extraction of metals from waste and waste residue, is a technical method of curing of the waste of resources. Its main anaerobic, aerobic composting [16]. Aerobic composting temperature between $50-65^{\circ} \mathrm{C}$, therefore also known as high-temperature composting. The anaerobic fermentation is mainly used to city life garbage processing [17], most of the decomposition of organic matter of the energy is stored in the methane, only a few will be converted to carbon dioxide, provides energy for microbial life activities. Is also a kind of biological treatment technology, has a high value of environmental protection and ecological use of anaerobic fermentation technology can not only avoid the waste directly to landfill generated after incineration of toxic substances, but also the ozone gas is reduced to the minimum limit. In general, the compost factory is the least, processing capacity of 3260000 tons. But in some places already in use. Zhou Chuanbin et al [18] made in recent years based on the metabolism of city ecosystem, research progress in the aspects of city life garbage carbon metabolism, heavy metals, nutrients and energy, analyzes the future direction of the research field of the need to focus on the. City Ecological metabolism studies direction such as garbage carbon metabolism study, living garbage heavy metal metabolism study, living garbage for further study.

\subsection{Energy Recovery: RDF and Incineration Power Generation}

Garbage derivative fuel, generally only garbage crushing, screening out the non combustible paper with after, waste plastics and other combustible based waste, or will fuel further crushing, drying and solid fuel worth. And waste incineration, RDF incineration technology has the advantages of stable combustion, low pollution two; processing field manufacturing and RDF in scattered, volume reduction and deodorization, convenient transportation and storage; you can add calcium oxide and coal in RDF, improve the calorific value, burning may reduce $\mathrm{HCI}$ emissions, reduce the corrosion tail the flue, while reducing dioxin emissions [19-21]. More than thearticle [22] of refuse derived fuel RDF (Refuse Derived Fuels) were performed to study the characteristics of the fluidized bed gasification, fluidized bed gasification experimental platform designed by the authors, the RDF gasification experiment results are analyzed, also analyzed the distribution of matter and energy gas production, and discussed the effect of increasing the intake temperature and different air preheating temperature. On the gas production, the tar gasification gas component, $\mathrm{RDF}$ as is, bottom ash and heavy metal content in fly ash. Zhang Lijing [23], the simulations are carried out to study the pyrolysis gasification characteristics of refuse derived fuel model and its application TG-DSC, TG, TGA and DSC analysis of pyrolysis and combustion conditions on three kinds of samples, the ignition, burnout, activation energy and combustion characteristic index characteristic parameters of the samples. And proposed the Gauss fitting model to quantitatively analyze the influence of each component, interaction of pyrolysis conditions results show, Gauss fitting than direct linear fitting in the prediction of DTG peak temperature is more accurate. And both have made certain achievements.

\section{Conclusion}

Collection and disposal of solid waste has been a number of research and development, but its utilization is slow. The author thinks, the resource utilization of solid wastes is fundamentally solve the problem, and the development of separation technology, biological treatment, plasma treatment and resource utilization of RDF and incineration technology brings hope for its resources, especially the plasma treatment and RDF derived fuel resources for solid waste incineration power generation technology have a very good prospect of industrialization.

\section{Acknowledgements}

This work is supported by Innovative training program of Chinese National college students (201410641009, 201410641014), Scientific Technology Foundation of Sichuan Province, P. R. China (2012GZ0114), Scientific Technology Foundation of Yibin City (2013ZSF012, 2014SF043) and Scientific Project of Yibin University (2010B10, 2013QD03).

\section{References}

[1] Chen Jie, Wang Qiannan, Ye Zhiping, et al. Low temperature plasma combined with stripping method to remove leachate [J]. Journal of chemical waste odor, 2012, 63 (11): 3660-3665.

[2] Li Jinhui, Nie Yongfeng, Bai Qingzhong. Research on industrial solid waste China $[\mathrm{J}]$. Journal of environmental science forecast, 1999 (06): 625-630.

[3] What flowers. Classification of the establishment of city living garbage collection $[\mathrm{J}]$. a new mode of environmental protection and recycling economy, 2012 (05): 15-17.

[4] Liu Shuzhi, Zhu Yuwu, Yang Yuhua, et al. Dian chi basin rural solid waste source classification collection and processing of system design $[\mathrm{J}]$. Yunnan environmental science, 2006 (S1): 162-164.

[5] Zhang Qi city solid waste harmless treatment way [J]. Chinese resources comprehensive utilization, 2012 (08): 26-29.

[6] Liao Lingjuan, Huang Na, Jiang Ming Hong, et al. The city solid waste by different treatment methods for carbon emissions analysis -- Taking Dong guan city as an example of a garbage incineration power plant $[\mathrm{J}]$. Anhui agricultural science, 2013 (16): 7287-7289.

[7] Wang Limin. Life garbage treatment process selection [J]. Shan xi architecture, 2013 (25). 
[8] Huang Binghui. Slag separation process of [J]. green technology of MSW incineration, 2013 (07): 215-217.

[9] Zhang Jing. The recycling of urban living garbage [J]. Resources Economization and Environment Protection, 2015 (10): 26.

[10] Li Zehui, Fu Xiaoru, Shen Kai, et al. Research of city life garbage sorting technology [J]. renewable resources and recycling economy, 2013 (06): 24-27.

[11] Nguyen. Countermeasures of [J]. status and treatment of solid waste pollution in China today Keyuan, 2011 (02): 34

[12] Chen Jiang. Non thermal plasma technology in wastewater treatment applications [J]. modern chemical industry, 2012 (06): 632-639.

[13] Liu Xin, Li Shengli, Li Mingshu. Feasibility study on applying straw resources $[\mathrm{J}]$. Anhui Agricultural Sciences thermal plasma technology, 2012 (17): 9200-9202.

[14] Zhou Dan. Plasma gasification technology of garbage disposal is the future direction of development of $[\mathrm{J}]$. Foreign energy, 2013 (09): 57

[15] Wang Mingfei, forest conditions. Plasma technology in waste treatment in the application of [J]. technology to the wizard, 2014 (05): 43-116.
[16] Liu Shanshan, Wu Shuang, Zhu Nanwen. The landfill leachate biological treatment technology research status and Prospect of [J]. Guangzhou chemical industry, 2014 (04): 8-10.

[17] Once. Organic solid waste composting microbiological mechanism of [J]. science and Technology Innovation Herald, 2013 (36): 28

[18] Zhou Chuanbin, Xu Wanying, Cao Aixin. Research progress of city life garbage metabolism in [M]. 2014

[19] XuJia, Yan Jianhua, Xiao Gang, et al. City life garbage gasification technology [J]. Chinese Science Bulletin, 2004 (06): 560-564.

[20] Shen Boxiong, Yao Qiang. Refuse derived fuel (RDF) technology [J]. Power system engineering, 2002 (03): 47-49.

[21] Li Yanji, Jiang Lu, Li Yulong, et al. Study on dynamic characteristics of refuse derived fuel gasification [J]. Power system engineering, 2013 (01): 5-8.

[22] Yu Dujiang. Refuse derived fuel (RDF) gasification characteristics of fluidized bed air experiment [D]. Dissertation of Zhejiang University, 2014.

[23] Zhang Lijing. Refuse derived fuel gasification pyrolysis mechanism model and Simulation of [D]. Dissertation of Zhejiang University, 2014. 